\title{
The long-term monitoring and evaluation of cement-based grout used to govern the water seepage of karst caves in China
}

\author{
Shiqiang Fang ${ }^{1}$, Bingjian Zhang ${ }^{1,2^{*}}$ (I) and Kun Zhang ${ }^{3}$
}

\begin{abstract}
Water seepage is the primary cause of stone carvings corrosion in karst caverns, which is typically treated with cement-based grout intervention. In this paper, long-term monitoring (more than 1 1/2 years) was carried out in Qinglin cave and Yanxia cave in Hangzhou, China, to quantitatively evaluate the advantages and disadvantages of ordinary Portland cement- and superfine cement-based grout intervention. Results showed that both materials were efficient in preventing water seepage, reducing it by half after the grout interventions. Grout intervention had obvious efficacy in blocking off the strong water seepage points, at the same time decreasing seepage differences among seepage points. Ion Chromatography results suggested that the concentrations of $\mathrm{Ca}^{2+}, \mathrm{Cl}^{-}$and $\mathrm{SO}_{4}{ }^{2-}$ in the seeped water in both caves increased after intervention, and the concentration of $\mathrm{SO}_{4}{ }^{2-}$ in the seeped water after superfine cement application in Qinglin cave was much more than that in the seeped water in Yanxia cave, where ordinary Portland cement was applied. Therefore, using superfine cement may bring more potential risks than ordinary Portland cement. However, X-ray diffraction (XRD) and conductivity analysis results presented that these ions seemly did not deposit on rock surfaces of the caves during the monitoring period.
\end{abstract}

Keywords: Cement grout intervention, Water seepage, Long-term monitor, Karst cave, Culture heritage

\section{Introduction}

Many paintings and stone carvings were created in caves like Elephanta Caves, Mogao Grottoes (莫高窟), and Bmyn Caves. However, under significant threats caused by various natural and man-made factors, the primary of which being water seepage [1-3]. Water seepage combined with acid gas can accelerate the weathering of landform and stone carvings [4]; sediments brought by seeped water could pollute the stone carvings and paintings [5]; salts in rock could dissolve in water, and lead to detrimental effects on paintings and stone carvings that reside on the surface of the rock [6]. Especially in the case of unstable rocks, internal water seepage could hazard the entire cave structure $[3,7]$, and once the cave collapses,

\footnotetext{
*Correspondence: zhangbiji@zju.edu.cn

${ }^{1}$ Department of Cultural Heritage and Museology, Zhejiang University,

Hangzhou 310028, People's Republic of China

Full list of author information is available at the end of the article
}

irreversible damage will be caused on the precious cultural artifacts.

Some common methods for treating water seepage are chemical grouting, vegetation removal, drainage construction, impermeable blankets covering, etc. Since the 1950s, a large number of grottoes in China have been grouted with cement materials, such as Longmen grottoes (龙门石 窟), Maijishan (麦积山), Dazu stone carvings (大足石刻) [8-10]. As is well known, cement-based materials have disadvantages in conservation and restoration of historical buildings and relics $[11,12]$. Thus, before applying grout interventions, the material properties and construction techniques should be well studied. However, most relevant researches focused on lab and short-term field tests, with mainly qualitative descriptions and short-term monitoring data $[2,8]$. Even though the monitoring system of cultural relics has become an indispensable part of cultural relic restoration projects, public reports on quantitative evaluation of the long-term effect of water seepage treatment
Springer Open

(c) The Author(s) 2020. This article is licensed under a Creative Commons Attribution 4.0 International License, which permits use, sharing, adaptation, distribution and reproduction in any medium or format, as long as you give appropriate credit to the original author(s) and the source, provide a link to the Creative Commons licence, and indicate if changes were made. The images or other third party material in this article are included in the article's Creative Commons licence, unless indicated otherwise in a credit line to the material. If material is not included in the article's Creative Commons licence and your intended use is not permitted by statutory regulation or exceeds the permitted use, you will need to obtain permission directly from the copyright holder. To view a copy of this licence, visit http://creativeco mmons.org/licenses/by/4.0/. The Creative Commons Public Domain Dedication waiver (http://creativecommons.org/publicdomain/ zero/1.0/) applies to the data made available in this article, unless otherwise stated in a credit line to the data. 
are relatively scarce. Zhou et al. [13] found that water seepage in Klippe (飞来峰 in Hangzhou, China) was greatly reduced 3 years after cement grout intervention, yet precipitated soluble salt was observed in the path of water seepage. Yang [14] evaluated the water seepage treatment effect in three sites (Qianxi temple (潜溪寺), Huangfu grottoes (皇甫公窟) and Lu dong (路洞)) of Longmen grottoes in Luoyang, China, and regarded that it was very difficult to block off water seepage effectively in large grottoes. Chen [15] summarized the water seepage treatment methods applied in the Double kilns (双窑) in Longmen grottoes since 2004, and found that water seepage was effectively reduced by changing the water transportation channel in the cracks through grout intervention. Deng [10] reviewed the 40 years of water seepage treating experience in $\mathrm{Dazu}$ stone carvings (Chongqing, China), and deemed that treatment methods should be carried out in accordance with specific water seepage conditions.

In view of the fact that a large number of caves in China have adopted or may continue to adopt cement-based materials to deal with water seepage in caves, quantitative evaluation on the long-term effects of cement grout intervention is necessary. In this work, monitoring data on cement grouts gathered over a time span of 1 1/2 years from two karst caves (Qinglin cave (青林洞) and Yanxia cave (烟霞洞)) in China was quantitatively analyzed, and the advantages and disadvantages of applying cement-based materials for water seepage treatment were discussed.

\section{Background}

\section{History}

The Qinglin cave and Yanxia cave are located in the West Lake scenic area (World Heritage) of Hangzhou, China. Since the 9th century, the ancient Chinese had been carving out stone statues of Mahayana Buddhas in these two caves till the 13th century and the 20th century respectively. To date, 178 statues of all sizes remained in Qinglin cave, and 15 statues in Yanxia cave.

\section{Environment}

Qinglin cave and Yanxia cave are two naturally formed karst caves generated in carbonatite. The straightline distance between these two caves is about $2.6 \mathrm{~km}$ (Fig. 1a), so their external environments are almost identical (damp and rainy). There are three geologicallyinduced subsidence areas in the northeast, the southeast, and the center of Qinglin cave (Fig. 1b), which exposed the interior of this cave to the outdoor environment from multiple directions. Thus, the temperature and the humidity inside this cave are close to the values outside. The relative humidity in Qinglin cave is often more than $70 \%$ all year round, and the maximum and minimum temperatures in a year are about $30{ }^{\circ} \mathrm{C}$ and $-2{ }^{\circ} \mathrm{C}$ respectively. Yanxia cave, on the other hand, has only one entrance (Fig. 1c), creating a highly humid environment deep inside the cave. Most times, the relative humidity in Yanxia cave is more than $80 \%$, and the temperatures ranged within $10-28{ }^{\circ} \mathrm{C}$ all year round.
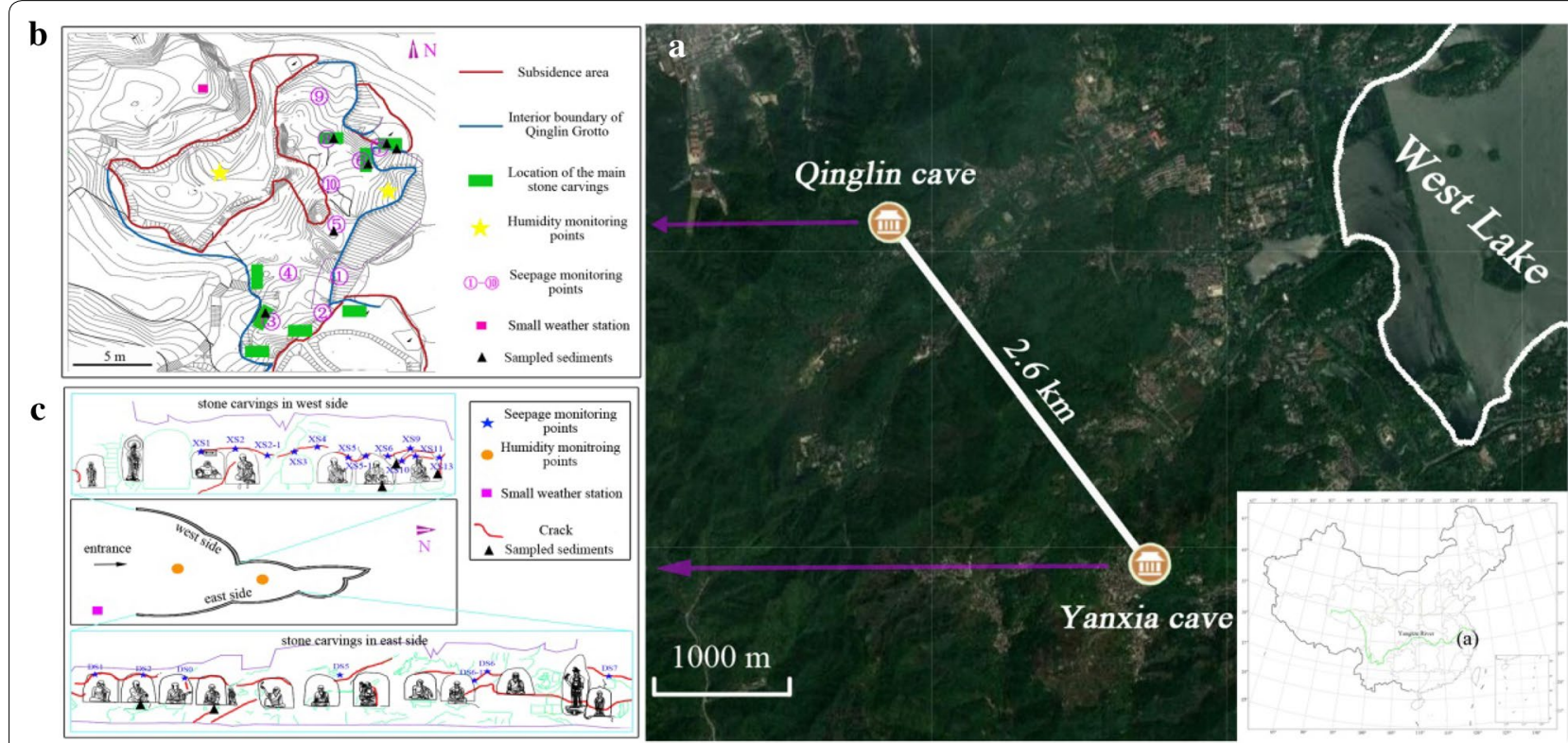

Fig. 1 The satellite image of Qinglin and Yanxia cave (a), the sketch maps and location of the monitor points in Qinglin cave (b) and Yanxia cave (c) 
Like many other karst caves, water seepage is one of the main factors affecting the stability of these two caves and the conservation of their stone carvings. Some detrimental effects caused by long-term water seepage on the surface of stone carvings in Qinglin cave and Yanxia cave are discoloring, microbial contamination and surface weathering (Fig. 2), calling for appropriate intervention.

\section{Intervention}

Since 2013, many projects focusing on the water seepage in these two caves have started successively, including geological exploration, material selection, disease survey and scheme design. Based on previous work, the water seepage in Qinglin cave and Yanxia cave derives mainly from meteoric precipitation. Therefore, chemical grouting and physical measures (laying impermeable blanket and digging drainage channel) are the main methods to govern the water seepage. In this work, two types of cement grouting materials were applied in the two caves: superfine cement-based grout in Qinglin cave, and ordinary Portland cementbased grout in Yanxia cave. The detailed compositions of these two cements were reported in a previous work [2]. As is well known, cement is a double-edged sword in the conservation of heritage sites [16]: although cement was not directly applied to stone carvings, soluble salts present in cement could possibly affect long-term preservation of the stone carvings. Thus, monitoring over a wide time span should be commenced to evaluate the advantages and disadvantages of cement grout intervention.

\section{Methods and experimental design \\ Field monitor}

Small integrated weather stations were set up on a vacant lot near both caves. In this work, only rainfall data was used, which was recorded automatically by a tippingbucket rainfall gauge with a recorder (JBD-1, Xuzhou Weisi Water Science and Technology Co., Ltd., China). The measurement accuracy was $0.5 \mathrm{~mm}$.

The values of water seepage were recorded manually. First, ten and nineteen water seepage observation points were chosen according to the distribution of stone inscriptions and permeable fractures before grout intervention in Qinglin cave and Yanxia cave, respectively (Fig. 1b, c). Then, the recorders counted the numbers of dripping water droplets for $1 \mathrm{~min}$ in the morning (7-9 a.m.). Each observation point was counted three times and then averaged. If the dripping water becomes a flow, grade I, II and III were used to express its magnitude.

All data were collected from June 2017 to December 2018 in Qinglin cave and from November 2016 to October 2018 in Yanxia cave.

\section{Lab analysis}

Soluble ions and sediments of seeped water were analyzed to reflect the possible harm of cement grout intervention, following the analytical procedures below:

\section{Sampling}

(a) Seeped water The seeped water samples were collected from these two caves before and after ( 1 and 12 months) grout interventions. In Qinglin cave, these water samples were gathered in June 2017, October 2018 and December 2018; in Yanxia cave, they were collected
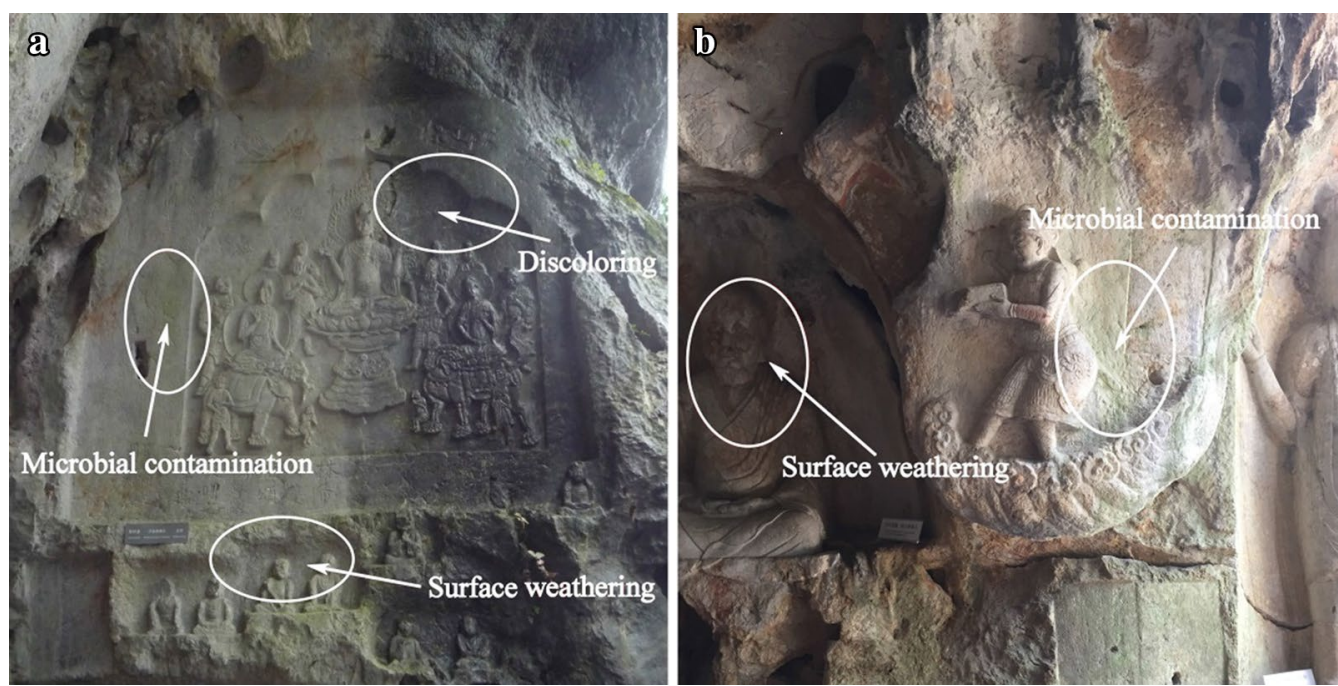

Fig. 2 Some diseases on stone carvings in the entrance of Qinglin cave (a) and Yanxia cave (b) 
in March 2017, September 2017 and August 2018. All samples were collected in the day after a moderate rain (rainfall between 20 and $40 \mathrm{~mm} / \mathrm{d}$ ) and stored in airtight centrifuge tubes $(50 \mathrm{ml})$. No fewer than five points were sampled at a time, and more than $30 \mathrm{ml}$ of water was collected at each point. Meanwhile, the rain drops in the same day were also collected.

(b) Sediments The sediments on the surface of rocks are collected by scalpel before and after grout intervention from the vicinity of the water seepage monitoring points (Fig. 1), basing on the color of the sediment (white, gray, and yellow). In Qinglin cave, the sediments were white, gray, and yellow, collected in June 2017 and December 2018; in Yanxia cave, they were white and light gray, collected in March 2017 and August 2018.

The hardened ( $28 \mathrm{~d}$ ) superfine cement-based grouting materials were also collected from the construction site as references.

\section{Soluble ions}

The category of soluble ions in the water seepage before and after the grout intervention was analyzed by Ion Chromatography (ICS-2100, Dionex, United States). Before the test, $1 \mathrm{ml}$ of liquid was taken from each seeped water sample, then the liquid from the same batch was mixed evenly. Through a proper concentration or dilution, the mixed fluids were analyzed by IC. Thus, the results reflected the average value of soluble ions in the water seepage at a particular time.

The $\mathrm{pH}$ values of the water seepage before and after the grout intervention were tested by a $\mathrm{pH}$ meter (FiveEasy ${ }^{\mathrm{TM}}$, METTLER TOLEDO, United States). Each sample was tested three times and the average values were determined.

\section{Sediments}

The compositions of the sediments at different stages were analyzed by X-ray powder diffraction (AXS D8 ADVANCE, Germany). The samples were first dried in oven at $55^{\circ} \mathrm{C}$ for $6 \mathrm{~h}$, then ground into powder using agate mortar before analysis. The wavelength and scanning speed of XRD analysis were 1.54 unit and $10^{\circ} 2 \theta$ $\min ^{-1}$ respectively.

The ion concentration of the sediments after grout intervention was determined by DDS-307 conductivity meter (Shanghai REX Instrument Factory). $1 \mathrm{~g}$ of each sediment sample powder was added in $50 \mathrm{~g}$ of deionized water, then the mixture was continuously stirred for $24 \mathrm{~h}$ with a magnetic mixer $(400 \mathrm{r} / \mathrm{min})$ before the conductivity tests. Each sample was tested 3 times and then averaged.

\section{Results and discussions \\ Water seepage \\ (a) Qinglin cave}

Figure 3 presents the complete data for water seepage and rainfall before and after grout intervention (from June 2017 to December 2018) in Qinglin cave.

Results showed that the water seepage was always positively correlated to rainfall throughout the monitoring period. When rainfall was below $10 \mathrm{~mm} / \mathrm{d}$ and there was no continuous raining, the water seepage was almost negligible. When the rainfall rose to $10-25 \mathrm{~mm} / \mathrm{d}$, the water seepage was often below $25 \mathrm{drop} / \mathrm{min}$. However, once the rainfall exceeded $25 \mathrm{~mm} / \mathrm{d}$, the pre-intervention data displayed that a continuous water current was observed at least one time at 8 monitoring points and the maximum water seepage grade reached grade III. After intervention, however, only in 3 monitoring points the ripping water became a flow, and the maximum water seepage grade reduced to grade II under the same condition, suggesting an effective water seepage control by grout intervention in Qinglin cave.

To analyze the efficacy of grout intervention in detail, the data of water seepage under different values of rainfall was plotted in Figs. 4 and 5. There were five rainfall levels throughout the monitoring period: non-rain, light rain $(<10 \mathrm{~mm} / \mathrm{d})$, moderate rain $(10-25 \mathrm{~mm} / \mathrm{d})$, heavy rain $(25-50 \mathrm{~mm} / \mathrm{d})$ and rainstorm $(>50 \mathrm{~mm} / \mathrm{d})$. However, since water seepage during rainfall below $10 \mathrm{~mm} / \mathrm{d}$ was negligible, only the last three conditions were addressed in the present study. Grade I, II and III were equal to 100 , 140 and $180 \mathrm{drop} / \mathrm{min}$ for comparison purpose in this section.

According to Fig. 4, the average value of water seepage increased by $3.7 \%$ after intervention during a rainstorm, while this value declined by 48 and 53\% after intervention during heavy rain and moderate rain respectively. These data indicated that the grout intervention worked well when the rainfall was below $50 \mathrm{~mm} / \mathrm{d}$, but was almost useless when this critical value was exceeded. Secondly, comparing with the data before grout intervention, the maximum value of water seepage declined from $180 \mathrm{drop} / \mathrm{min}$ (grade III) to $140 \mathrm{drop} / \mathrm{min}$ (grade II), and the minimum value of water seepage decreased to 0 drop/min after grout intervention under the three conditions. Thirdly, the change of median showed that the lower quartile increased by $100 \%$ and the upper quartile remained almost the same after grout intervention when the rainfall exceeded $50 \mathrm{~mm} / \mathrm{d}$. In the other two conditions, both the upper and lower quartile declined after grout intervention, respectively by 69 and $60 \%$ during heavy rain, and by 63 and $72 \%$ during moderate rain. For all three rainfall conditions, the differences between the upper and lower quartile decreased by 33,62 , and $58 \%$ 


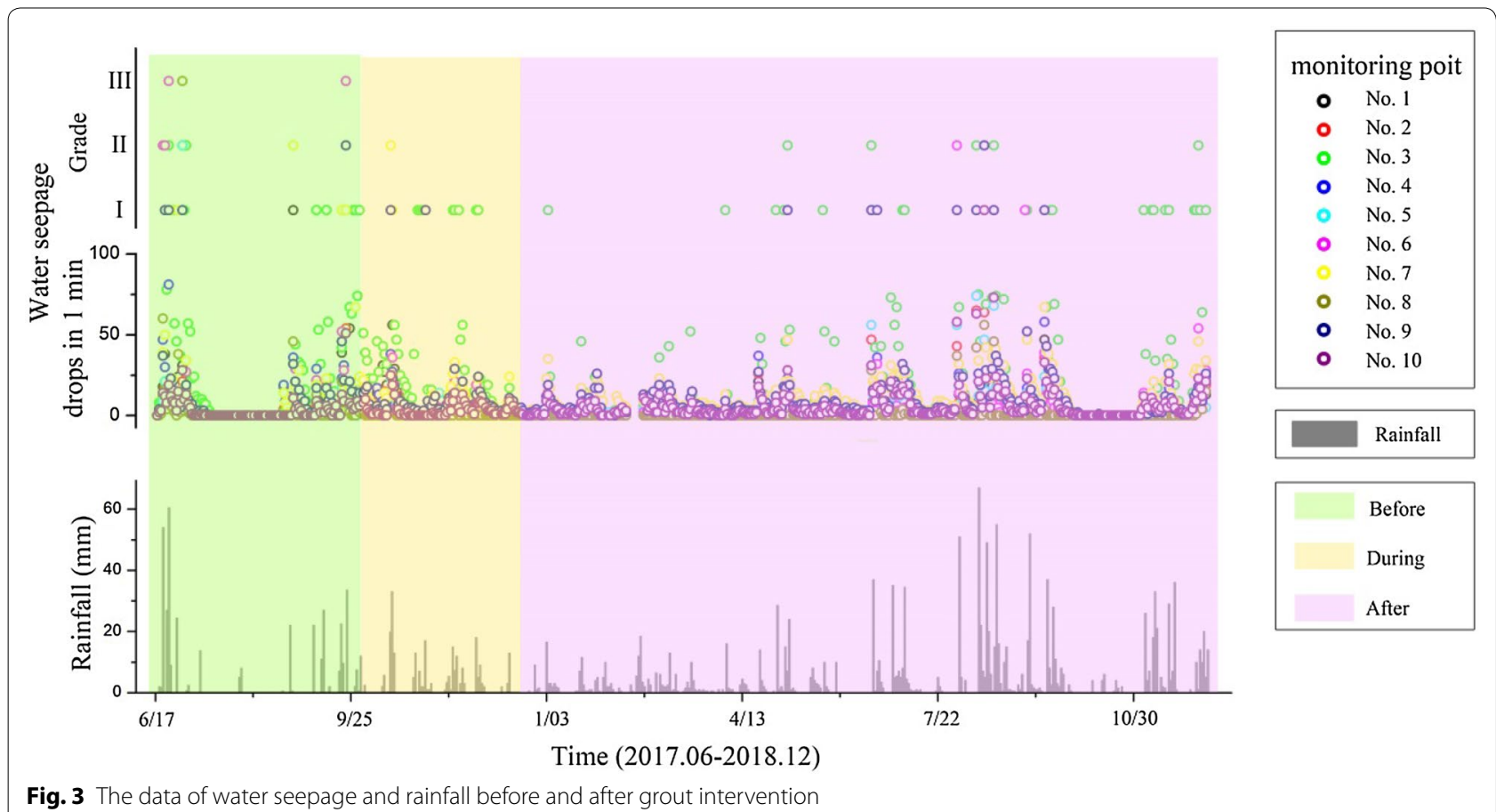

Fig. 3 The data of water seepage and rainfall before and after grout intervention

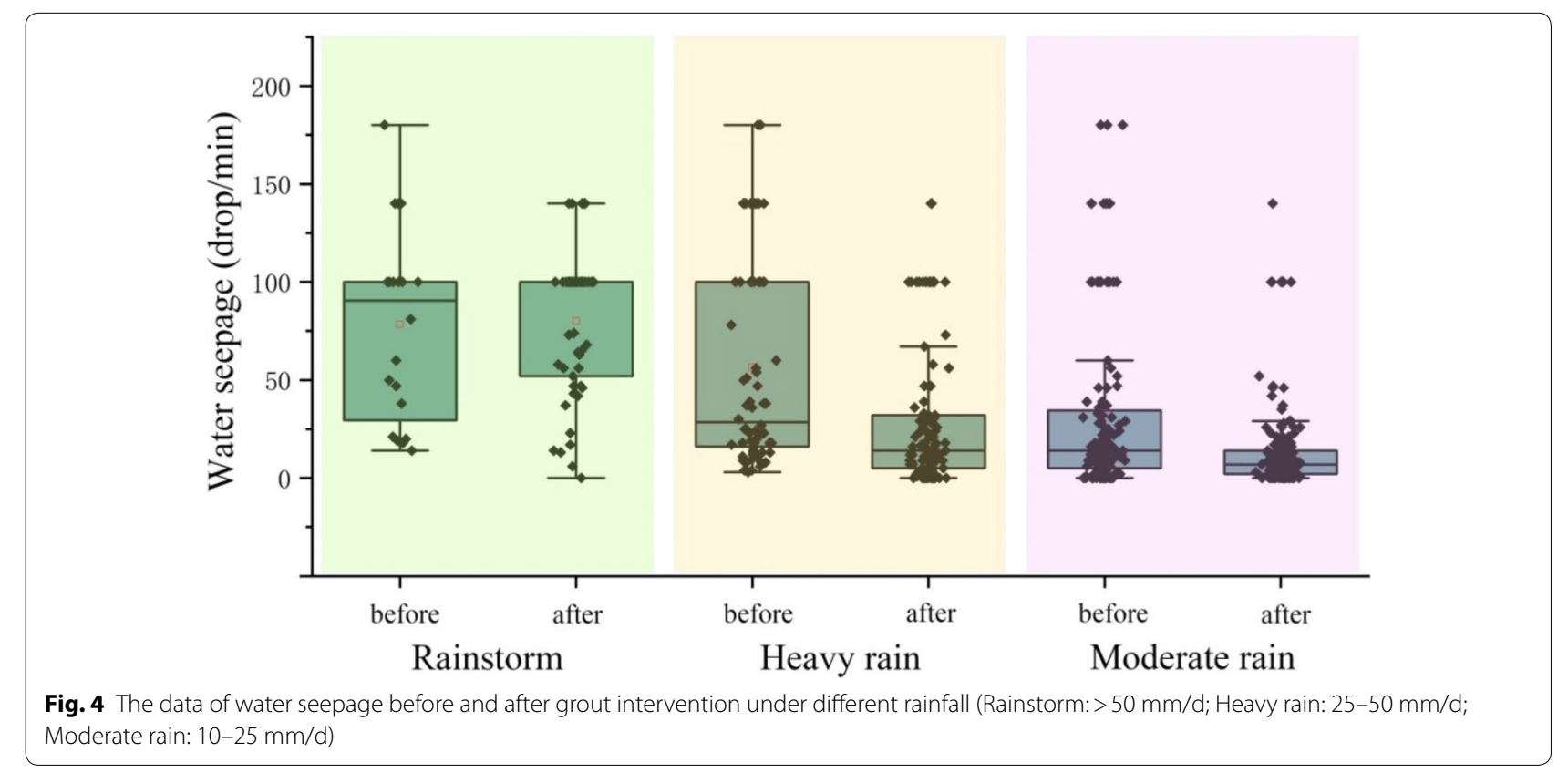

under rainstorm, heavy rain, and moderate rain conditions, respectively. The extremum and quartile changes indicated that grout intervention had obvious efficacy in blocking off the strong water seepage points, at the same time decreasing differences among seepage points.

Figure 5 shows the relationship between the grout intervention and the average values of each water seepage monitoring point under different rainfall conditions. The results demonstrated that, when the rainfall was over $50 \mathrm{~mm} / \mathrm{d}$ after grout intervention, the water seepage increased at 5 monitoring points (nos. 1, 2, 4, 7, 10). These points all had relatively small average water seepage values before intervention. For instance, the average values of water seepage at points no. 2 and no. 


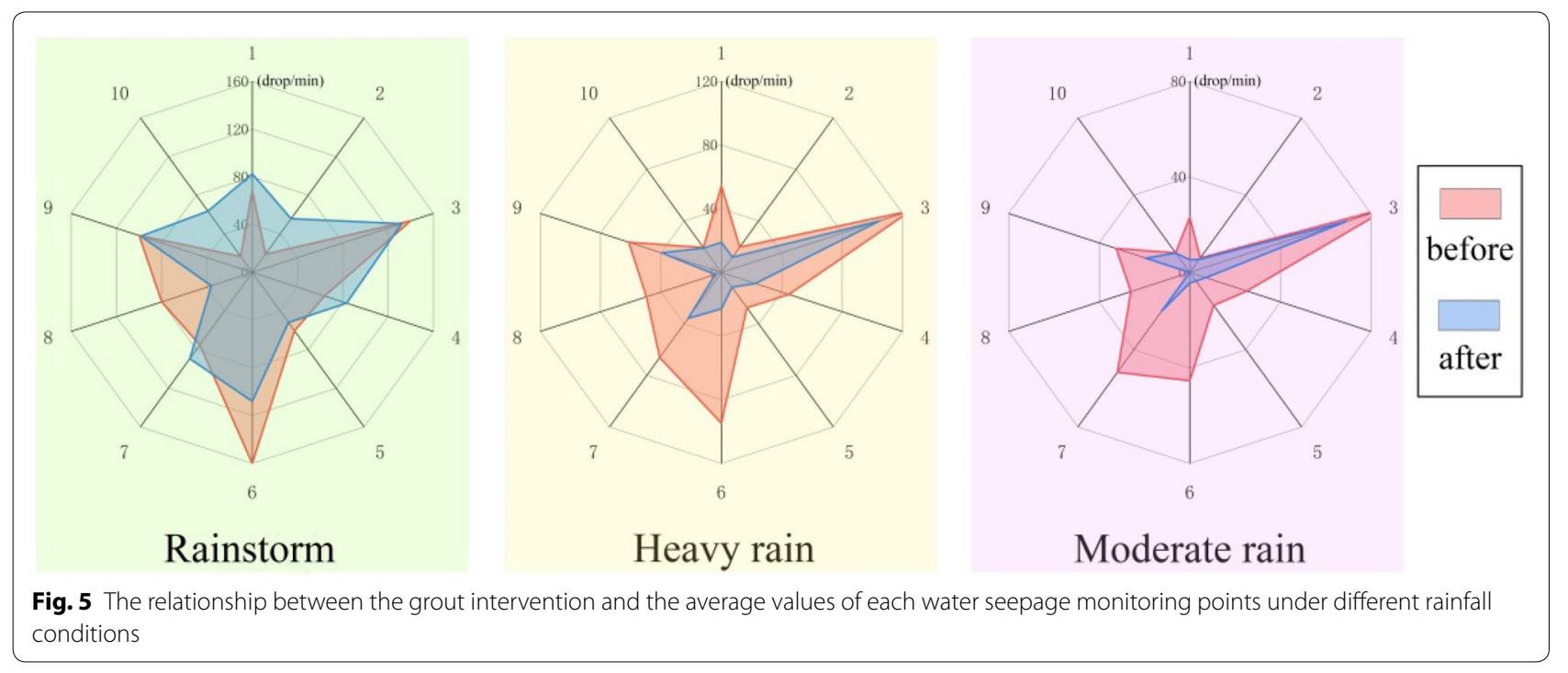

10 (18 and $16 \mathrm{drop} / \mathrm{min}$ before intervention) increased to 57 and $64 \mathrm{drop} / \mathrm{min}$ after intervention. This phenomenon may be due to the sealing by grout intervention at points with previously higher water seepage values. When heavy rain came, the rainwater had no time to veer from the original path and flew out from these points. The data for water seepage under rainfall below $50 \mathrm{~mm} / \mathrm{d}$ showed that all seepage values declined after grout intervention, by more than $80 \%$ at 6 points and by less than $10 \%$ at 2 points. In general, although the grout intervention did not completely cut off water seepage, its effect was excellent under normal rainfall conditions (below $50 \mathrm{~mm} / \mathrm{d}$ ).

\section{(b) Yanxia cave}

Figure 6 presents the complete data for water seepage and rainfall before, during and after grout intervention (from November 2016 to October 2018) in Yanxia cave.

The pre-intervention data showed that when the rainfall was below $10 \mathrm{~mm} / \mathrm{d}$ and there was no sustained rain, the water seepage was almost negligible. Once the rainfall exceeded $10 \mathrm{~mm} / \mathrm{d}$, the water seepage became apparent and there was no clear proportional relationship between water seepage and rainfall any more. At least ten monitoring points experienced water seepage

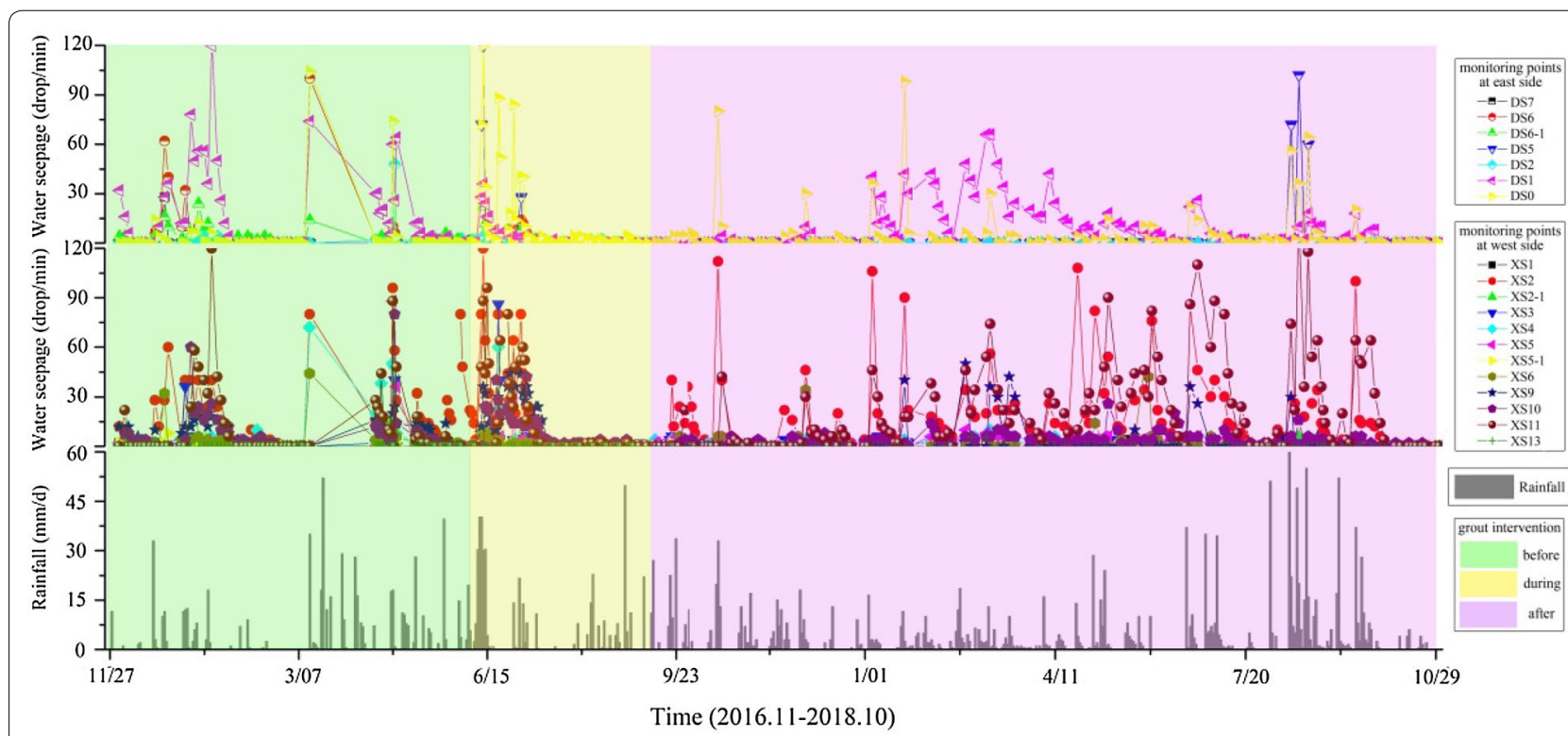

Fig. 6 The data of water seepage and rainfall before, during and after grout intervention in Yanxia cave 
exceeding $60 \mathrm{drop} / \mathrm{min}$ one time, and the maximum water seepage reached $120 \mathrm{drop} / \mathrm{min}$.

The post-intervention data displayed that the relationship between water seepage and rainfall could be divided into two stages. Within about 3 months after intervention, the water seepage was mainly concentrated at two monitoring points, and there was little water seepage in the remaining points although there was heavy rain during this time. After 3 months, however, the proportion of water seepage began to increase in early 2018, especially when the rainfall exceeded $15 \mathrm{~mm} / \mathrm{d}$. During this time, at least 5 monitoring points experienced water seepage exceeding $60 \mathrm{drop} / \mathrm{min}$ one time, and the maximum water seepage was back to $120 \mathrm{drop} / \mathrm{min}$. Such seepage increase was possibly induced by the floating soil and vegetation (water-storage and water-holding materials) above and around the cave, which had been previously removed during the intervention process, but re-grew as time went by. Certainly, we cannot rule out the possibility that fissures may be newly formed between grouting materials and rocks with the growth of time. This would require further exploration and research in the future.

Moreover, the monitoring data from June to October 2017 in Fig. 6 showed that the intervention had excellent efficacy during those 4 months, but increased thereafter. Therefore, a monitoring period of at least 1 year is necessary when evaluating the efficacy of grout intervention.

In order to analyze the efficacy of grout intervention in detail, the data of water seepage under different values of rainfall were also discussed in Yanxia cave. The results were listed in Figs. 7 and 8.

First, the results (Fig. 7) show that, the minimum, lower quartile and median of water seepage were always zero during the whole monitoring period under

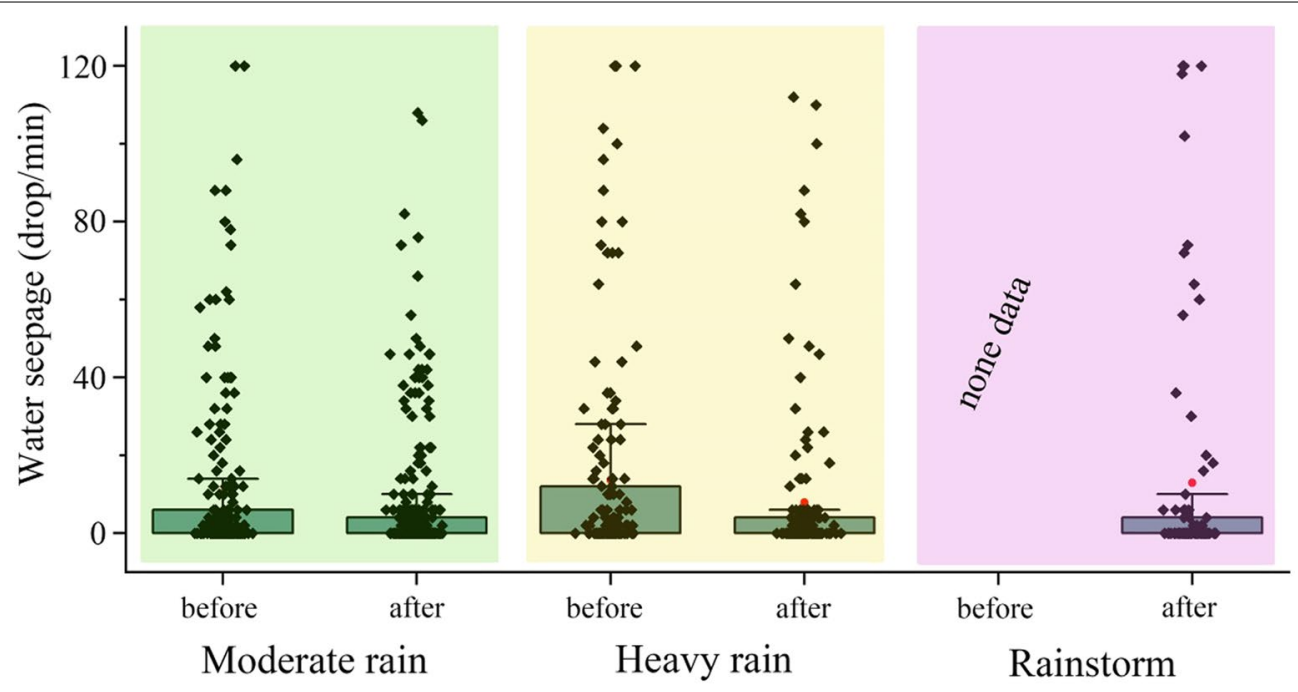

Fig. 7 The statistical results of water seepage before and after grout intervention in Yanxia cave

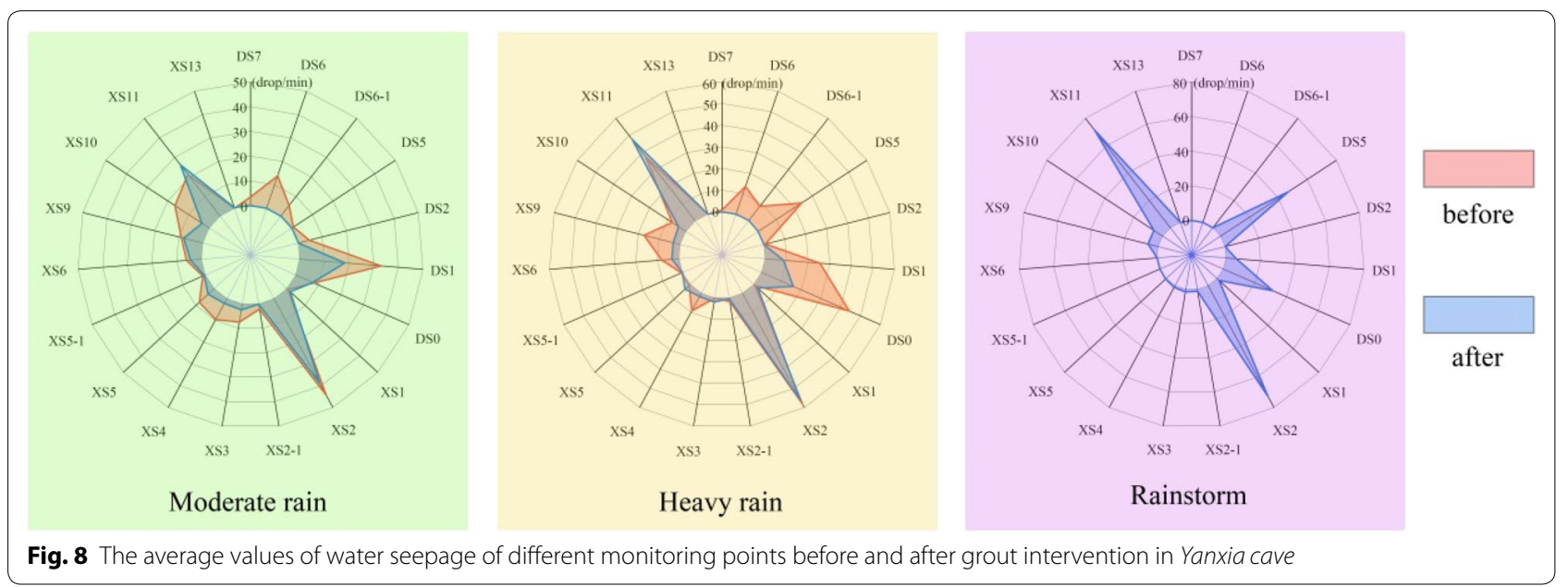


different rainfall conditions, indicating that the lower limit of water seepage in Yanxia cave was not affected by the grout intervention. However, the maximum and upper quartile of water seepage decreased after grout intervention. For instance, under moderate rain and heavy rain, the maximum values of water seepage declined by 10 and $7 \%$ respectively after intervention, the upper quartile declined by 33 and $67 \%$, and the average value declined by 39 and $43 \%$. Thus, the grout intervention had positive effects especially on blocking off the strong water seepage points in Yanxia cave, in the meantime decreased the upper limit and discreteness of water seepage.

It should be pointed out that due to the lack of preintervention data, the effect of grout intervention under rainstorm couldn't be concluded here. (Its maximum, upper quartile and average value were 144, 4 and 6.5 drop/min, respectively.)

The average water seepage before and after intervention at each monitoring point under different rainfall conditions was shown in Fig. 8. After grout intervention, the water seepage declined by more than $60 \%$ at 11 and 12 points under moderate rain and heavy rain respectively, while 5 points ( $26 \%$ of the total monitoring points) did not have water seepage. Although the water seepage increased at 3 and 4 points after grout intervention under the above two rainfall conditions respectively, the increased water seepage would not exceed $2 \mathrm{drop} / \mathrm{min}$ (except no. XS11, where the water seepage increased by $8 \mathrm{drop} / \mathrm{min}$ ). Thus, overall, the grout intervention had more positive than negative effects on reducing water seepage.
Moreover, as found in Qinglin cave, the grout intervention also affected the water seepage path. Combined with the data in Fig. 5, it could be concluded that, neither superfine cement nor ordinary Portland cement could completely seal the cracks, resulting in the change of water seepage path. Whether the change of the water seepage distribution and path caused by the grout intervention would bring new problems needs studying in follow-up works.

\section{Potential risks}

The XRD patterns of the raw superfine cement-based grout (Fig. 9a) showed that the main crystal forms were calcite, dicalcium silicate, and tricalcium silicate. In the hardened superfine cement-based grout (Fig. 9b), the primary crystal forms were calcite, dehydrate gypsum, portlandite, and tobermorite. Because the grouting cracks are usually narrow and long, the lack of $\mathrm{CO}_{2}$ made it difficult for portlandite in the hardened cement grout to form calcium carbonate. The soluble dehydrate gypsum and portlandite could transfer with seeped water, possibly affecting the preservation of the stone inscriptions in the cave. Thus, the potential risks of using cement-based materials were evaluated through soluble ions and sediments in these two caves before and after intervention.

\section{Soluble ions}

The ion chromatography analysis results (Table 1) revealed that the major ions in the slightly acidic rainwater $(\mathrm{pH}=5.91)$ were $\mathrm{K}^{+}, \mathrm{Ca}^{2+}, \mathrm{Cl}^{-}$and $\mathrm{SO}_{4}{ }^{2-}$ (respective concentrations at 4.53, 6.04, 3.78 and
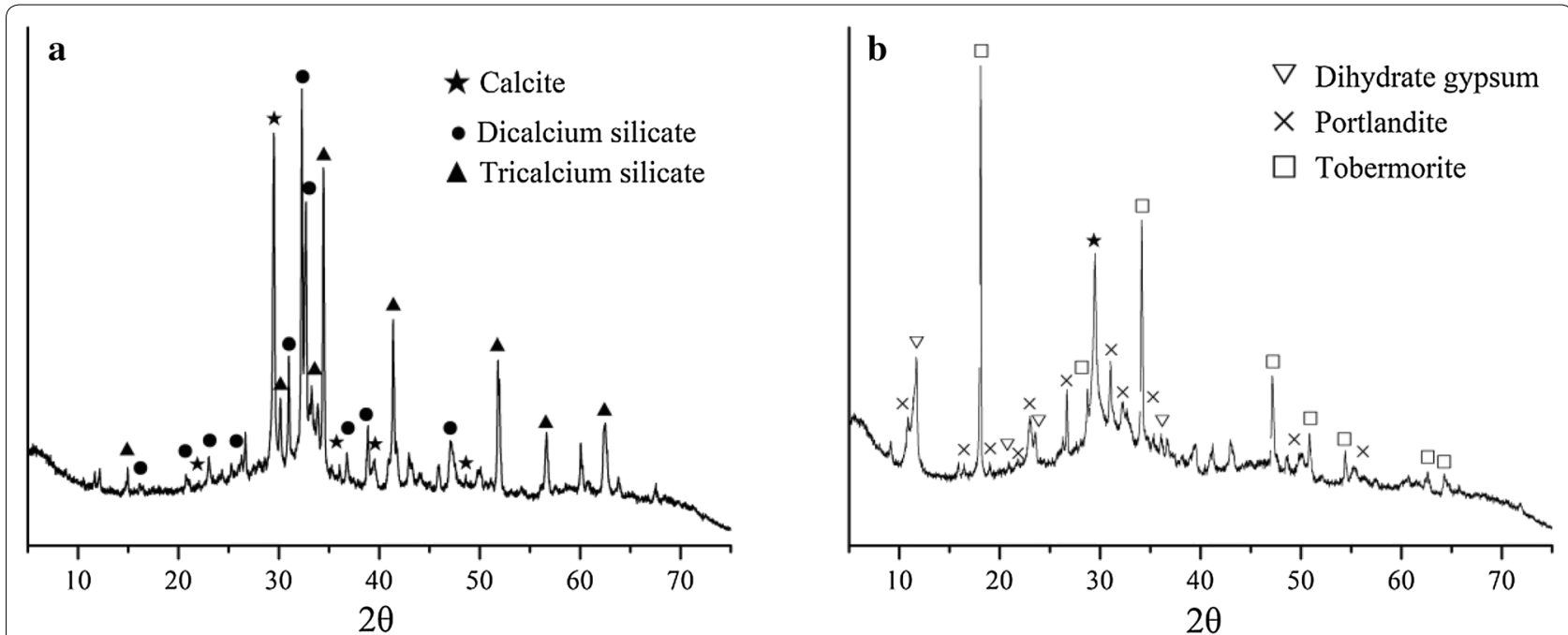

Fig. 9 The XRD patterns of cement grouting material, where $\mathbf{a}$ is raw superfine cement-based grout and $\mathbf{b}$ is hardened superfine cement-based grout (28d) 
Table 1 The concentrations of main ions in the water seepage at different stages

\begin{tabular}{|c|c|c|c|c|c|c|c|}
\hline \multirow[t]{3}{*}{ Content } & \multicolumn{7}{|c|}{ Concentration (mg/l) } \\
\hline & \multirow[t]{2}{*}{ Rainwater } & \multicolumn{3}{|c|}{ Water seepage at Qinglin cave } & \multicolumn{3}{|c|}{ Water seepage at Yanxia cave } \\
\hline & & $\begin{array}{l}\text { Before } \\
\text { intervention }\end{array}$ & After 1 month & After 12 months & $\begin{array}{l}\text { Before } \\
\text { intervention }\end{array}$ & After 1 month & After 12 months \\
\hline $\mathrm{Na}^{+}$ & 0.73 & 1.77 & 1.56 & 3.44 & 1.38 & 2.74 & 3.44 \\
\hline $\mathrm{K}^{+}$ & 4.53 & - & 1.95 & 4.29 & 1.10 & 1.66 & 1.32 \\
\hline $\mathrm{Mg}^{2+}$ & 0.55 & 0.33 & 0.40 & 0.43 & 0.43 & 0.41 & 0.42 \\
\hline $\mathrm{Ca}^{2+}$ & 6.04 & 39.55 & 63.06 & 83.60 & 31.00 & 60.99 & 64.86 \\
\hline $\mathrm{Cl}^{-}$ & 3.78 & 4.55 & 18.26 & 10.65 & 3.01 & 16.29 & 7.19 \\
\hline $\mathrm{SO}_{4}{ }^{2-}$ & 3.09 & 18.10 & 33.48 & 25.34 & 13.68 & 24.87 & 16.96 \\
\hline $\mathrm{pH}$ & 5.91 & 7.12 & 7.26 & 7.43 & 7.32 & 7.46 & 7.63 \\
\hline
\end{tabular}

$3.09 \mathrm{mg} / \mathrm{l})$. Before intervention, the concentrations of $\mathrm{Ca}^{2+}$ and $\mathrm{SO}_{4}{ }^{2-}$ in seeped water of Qinglin cave increased dramatically comparing with the rainwater (by 555 and $486 \%$ respectively), while the concentrations of other ions had small changes; meanwhile, the $\mathrm{pH}$ of the seeped water became slightly alkaline $(\mathrm{pH}=7.12)$. The concentrations of ions in the rainwater which permeated into the Yanxia cave also showed a similar pattern. This phenomenon might be caused by the ion-exchange of the rainwater with the sediments (e.g. soil, remains of plants, microorganism) in the cracks and surfaces of the rocks.

In general, the data after the grout intervention showed increase of almost all the ions in the seeped water in both caves. Among them, the changes of $\mathrm{Ca}^{2+}, \mathrm{Cl}^{-}$and $\mathrm{SO}_{4}{ }^{2-}$ were most obvious. In Qinglin cave, these ions respectively increased by 59,383 and $85 \% 1$ month after intervention, and by 111, 134 and $40 \% 12$ months after intervention. In Yanxia cave, they increased by 97,441 and $82 \%$ ( 1 month after), and 109, 139 and 24\% (12 months after), respectively. These results showed that, even after 12 months postintervention, the concentrations of $\mathrm{Ca}^{2+}, \mathrm{Cl}^{-}$and $\mathrm{SO}_{4}{ }^{2-}$ did not level off, and the concentration of $\mathrm{Ca}^{2+}$ even increased during the monitoring time. These findings suggest that these soluble ions might migrate with water seepage, accumulate in some places, and may finally pose a potential threat to the preservation of stone carvings.

In addition, it must be stressed out that 12 months after intervention, the concentration of $\mathrm{SO}_{4}{ }^{2-}$ in the seeped water in Qinglin cave was much higher than that in Yanxia cave. This may be due to the higher sulfate content in raw superfine cement, as also reported in the previous study [2]. Therefore, the application of superfine cement-based materials is not recommended to deal with water seepage in this field.

\section{Sediments}

(a) XRD analysis The XRD patterns of the sediments on rock surfaces in Qinglin and Yanxia cave are shown in Figs. 10 and 11, respectively.

In general, the main colors of the sediments on the surface of the rocks near the seepage points in Qinglin cave were white, gray, and yellow, in Yanxia cave they were white and light gray. Figure 10 showed that, before grout intervention in Qinglin cave, the main crystal forms in white sediments was calcite, in gray sediments were calcite, quartz and gypsum, and in yellow sediments were quartz and calcite. Figure 11 showed that in Yanxia cave, the main crystal form in white and light gray sediments was calcite and small amounts of quartz. According to the colors and crystal forms, the white sediments might be the decomposition product of calcium bicarbonate (from the carbonatite reaction of carbon dioxide and water). The gypsum in the gray sediments was possibly the product of carbonatite reacting with $\mathrm{SO}_{2}$ under humid conditions, because there was no previous chemical intervention. Quartz was mostly from the soil that had been washed down from the top of the mountain by seeped water. After grout intervention, Figs. 10 and 11 showed that the main crystal forms in the sediments in these two caves were calcite or a mixture of calcite and quartz. There was no crystal form relating to the ordinary Portland cement or superfine cement.

(b) Conductivity Figure 12 shows the conductivity of the sediments on the rock surfaces in Qinglin and Yanxia cave. The results revealed that, after intervention, the conductivity of the sediments which were collected from vicinity of the water seepage points, ranged from 140 to 


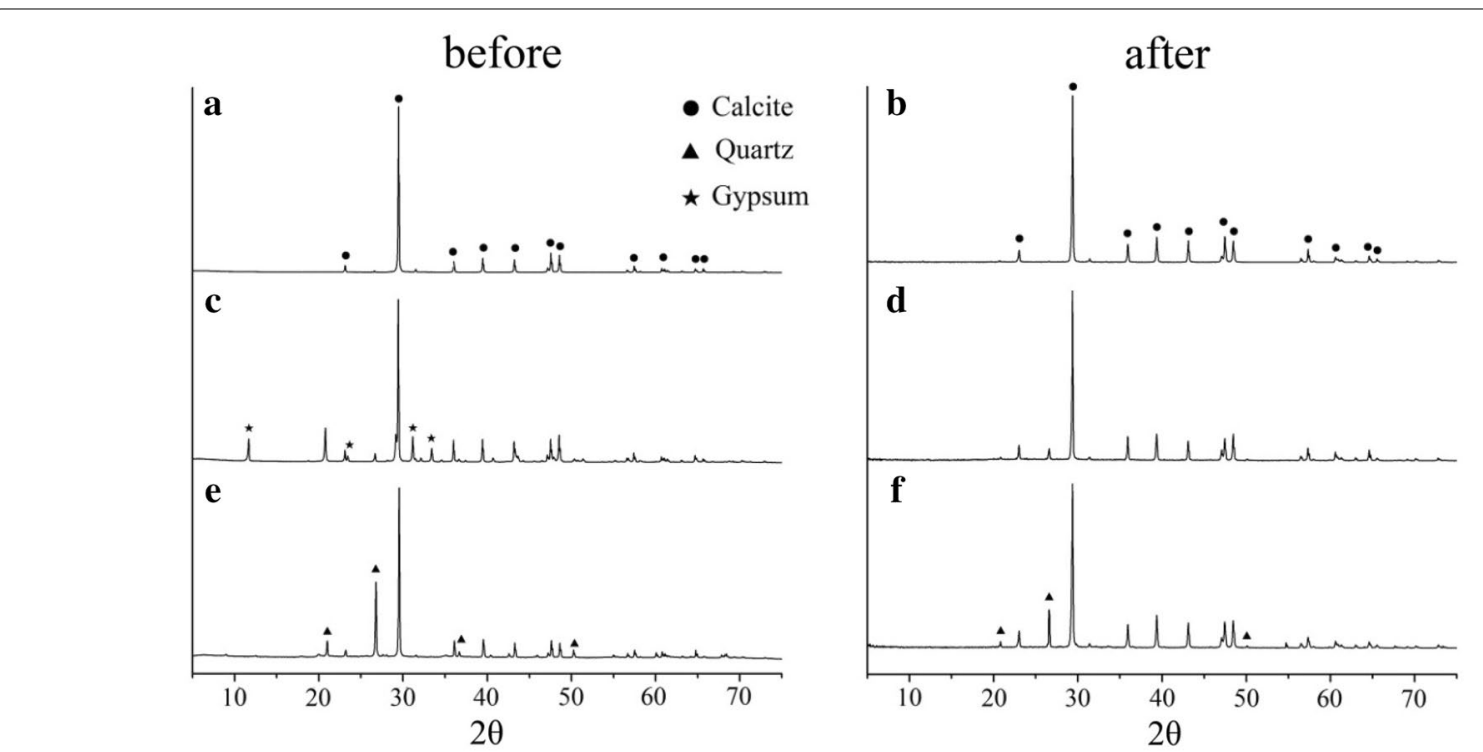

Fig. 10 The XRD patterns of different sediments before (June 2017) and after (December 2018) grout intervention in Qinglin Cave, where a and b are white sediments, $\mathbf{c}$ and $\mathbf{d}$ are gray sediments, and $\mathbf{e}$ and $\mathbf{f}$ are yellow sediments
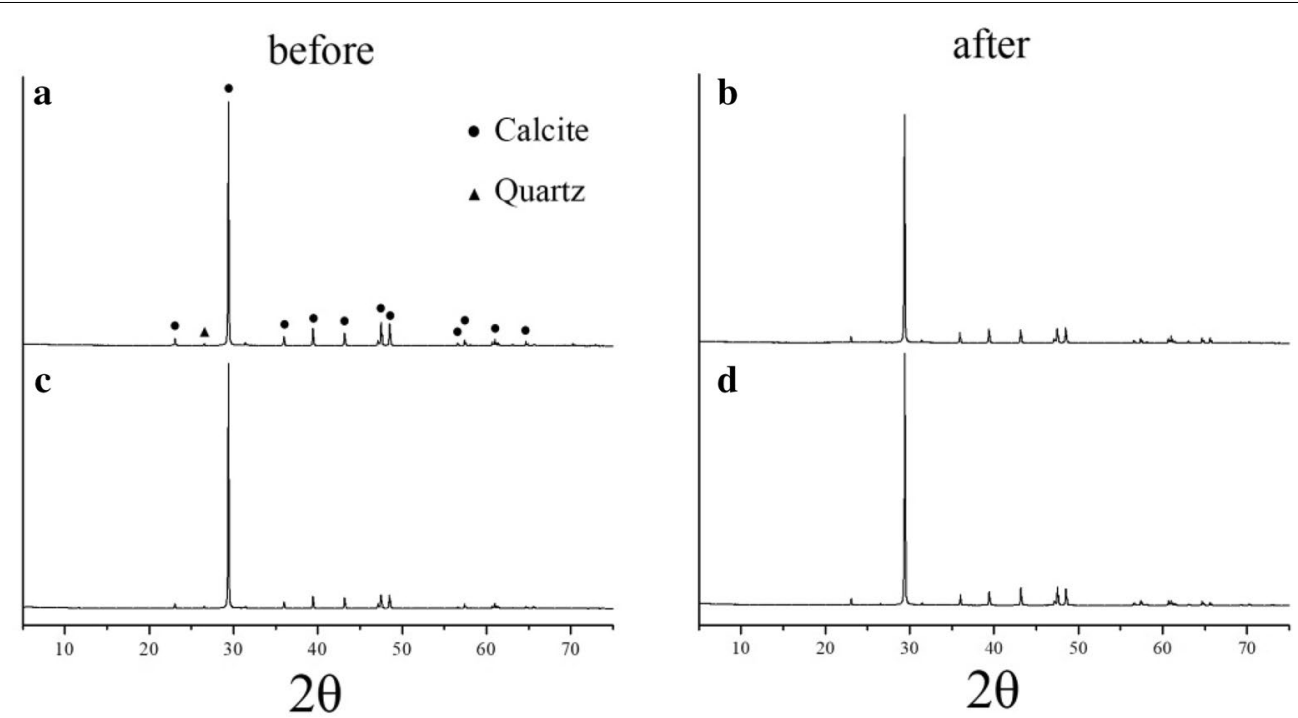

Fig. 11 The XRD patterns of different sediments before (March 2017) and after (August 2018) grout intervention in Yanxia Cave, where $\mathbf{a}$ and $\mathbf{b}$ are white sediments, $\mathbf{c}$ and $\mathbf{d}$ are light gray sediments

$160 \mu \mathrm{S} / \mathrm{cm}$, showing only slight changes comparing with the pre-intervention data (130 to $160 \mu \mathrm{S} / \mathrm{cm})$. Additionally, the conductivity of the sediments which were collected from the niche for Buddha, where water seeped through, ranged from 110 to $150 \mu \mathrm{S} / \mathrm{cm}$.

According to the above XRD and conductivity tests, although the values of $\mathrm{Ca}^{2+}$ and $\mathrm{SO}_{4}{ }^{2-}$ in the seeped water were significantly higher after grout intervention and did not decrease during the monitoring period, these soluble ions did not accumulate on the surfaces of the rocks in these two caves. It is possible that the soluble ions ran off quickly with the seeped water and posed no harm. However, since it was also possible that the amount of the sediment formed by the soluble ions was too little within the monitoring period, future monitoring is still necessary. 

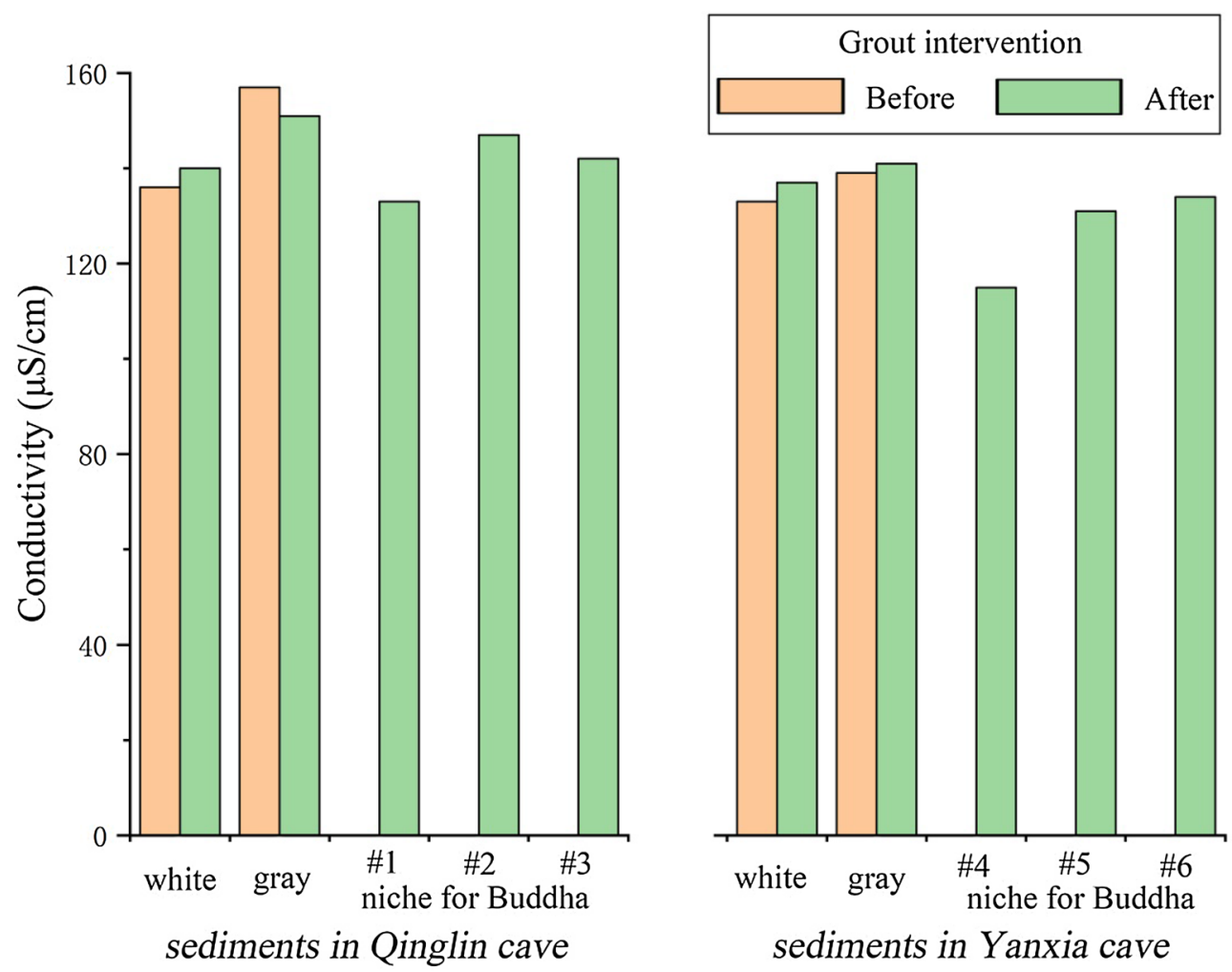

Fig. 12 The conductivity of different sediments before (March 2017) and after (August 2018) grout intervention in Qinglin and Yanxia cave

\section{Conclusion}

This work presented the results obtained from the longterm monitoring of Qinglin cave and Yanxia cave before and after cement grout intervention between 2017 and 2018. Through the evaluation of efficacy and potential risks of the grout intervention, the following conclusions can be made:

1. The monitoring data of Qinglin cave showed that the average water seepage was almost reduced by half after grout intervention. The analysis of extremum and quartile indicated that grout intervention had an apparent efficacy to block off strong water seepage points. Although grout intervention did not completely cut off water seepage, its effect was excellent under normal rainfall (below $50 \mathrm{~mm} / \mathrm{d}$ ).

2. The monitoring data of Yanxia cave showed that $26 \%$ of the total monitoring points did not have water seepage after grout intervention. The analysis of extremum and quartile displayed that grout intervention mainly decreased the upper limit and discreteness of water seepage. Moreover, the monitoring data of this cave revealed that the intervention had excellent effect in the first few months (about 3-4 months) after intervention, but increased there- after. Therefore, monitoring lasting for at least 1 year should be carried out when evaluating the efficacy of grout intervention in this field.

3. The grout intervention changed the trend of water seepage and decreased the differences among seepage points in these two caves. However, it remains to be investigated whether the changes will lead to new problems. In general, regardless of other factors (exploration, geology, construction personnel, etc.), both ordinary Portland cement-based and superfine cement-based grouting materials achieved very similar efficacy of grout intervention in this study.

4. The periodic sampling analysis in the lab revealed that, the concentration of $\mathrm{Ca}^{2+}, \mathrm{Cl}^{-}$and $\mathrm{SO}_{4}{ }^{2-}$ rapidly increased 1 month after intervention in these two caves. And after 12 months, the concentrations of these ions were still higher than those before intervention. It must be stressed out that the concentration of $\mathrm{SO}_{4}{ }^{2-}$ in the seeped water in Qinglin cave was much higher than that in Yanxia cave 12 months after intervention.

5. In view of the two grouting materials applied in this work, although superfine cement had better fillibility than ordinary Portland cement, it did not show a better performance in treating water seepage, and may 
even bring more potential risks instead. Therefore, in future work, other parameters besides the cementbased grouting material itself should be considered to improve the efficacy of grout intervention in this field.

\begin{abstract}
Abbreviations
XRD: X-ray diffraction; IC: Ion chromatography.
\end{abstract}

\section{Acknowledgements}

The authors thank the Lingyin Management Office and Qianjiang Management Office for their help in the field monitoring.

\section{Authors' contributions}

SF: investigation, experiment, data analysis, writing-original draft preparation. BZ: conceptualization, methodology, writing-reviewing and editing. $\mathrm{KZ}$ : writing-reviewing and editing. All authors read and approved the final mansuscript.

\section{Funding}

This research is supported by Zhejiang Provincial Administration of Cultural Heritage (2017) and China Postdoctoral Science Fund (2018M630660).

\section{Availability of data and materials}

Available upon request by the authors.

\section{Ethics approval and consent to participate}

This article does not contain any studies with human participants or animals performed by any of the authors.

\section{Consent for publication}

The consent for the publication of details and images in the manuscript are obtained from all participants.

\section{Competing interests}

No part of this paper has been published or submitted elsewhere. No conflict of interest exits in the submission of this manuscript. We acknowledge that this paper has complied with the submission declaration, and any necessary permission has been obtained. The authors declare that they have no known competing financial interests or personal relationships that could have appeared to influence the work reported in this paper.

\section{Author details}

1 Department of Cultural Heritage and Museology, Zhejiang University, Hangzhou 310028, People's Republic of China. ${ }^{2}$ Department of Chemistry, Zhejiang University, Hangzhou 310027, People's Republic of China. ${ }^{3}$ School of Cultural Heritage, Northwest University, Xi'an 710069, People's Republic of China.

\section{References}

1. Li HS, Wang WF, Zhan HT, et al. Water in the Mogao Grottoes, China: where it comes from and how it is driven. J Arid Land. 2015;7:37-45.

2. Fang SQ, Zhang K, Zhang BJ, et al. Evaluation of cement-based grout for reinforcing unsafe rocks of stone carvings at Hangzhou Klippe in China. J Mater Civ Eng. 2019;31:05018005.

3. Pujari PR, Soni A, Padmakar C, et al. Ground penetrating radar (GPR) study to detect seepage pathways in the Ajanta Caves in India. Bull Eng Geol Environ. 2014:73:61-75.

4. Zhao Y, Li MY, Wei X, et al. Quantitative analysis of the water of crystallization of gypsum by near-infrared spectroscopy in Yungang Grottoes. Anal Methods. 2015;7:8271-6.

5. Fernandez-Cortes A, Sanchez-Moral S, Canaveras JC, et al. Variations in seepage water geochemistry induced by natural and anthropogenic microclimatic changes: implications for speleothem growth conditions. Geodin Acta. 2009:22-23:1-13.

6. Giustetto R, Moschella EM, Cristellotti M, et al. Deterioration of building materials and artworks in the 'Santa Maria della Stella' church, Saluzzo (Italy): causes of decay and possible remedies. Stud Conserv. 2017:62:474-93.

7. Guo QL, Wang XD, Zhang HY, et al. Damage and conservation of the high cliff on the Northern area of Dunhuang Mogao Grottoes, China. Landslides. 2009:6:89-100.

8. Yang SJ, Pi L, Fang Y, et al. Research on metakaolin and micro fine cement composite grouting material in Longmen Grottoes. Stud Cave Temples. 2013:4:393-404 (in Chinese)

9. Dong GQ. Anchoring the cliff and excavating diversion canal-the reinforcement and water seepage treatment project in Maiji Grottos, China. Cult Herit. 2016:13:70-4 (in Chinese)

10. Deng ZJ. Review the conservation works in Dazu Stone Carving in the past 40 years. Sichuan Cult Relics. 1994:11:41-8 (in Chinese)

11. Moropoulu A, Bakolas A, Bisbikou K. Investigation of technology of historic mortars. J Cult Herit. 2000;1:45-58.

12. Callebout K, Elsen J, Van Balen K, et al. Nineteenth century hydraulic restoration mortars in the Saint Michail's Church (Leuven, Belgium) natural hydraulic lime or cement? Cement Concrete Res. 2001;31:397-403.

13. Zhou K, Zhang BJ, Wang LY, et al. Evaluation research of southern rainy area grottos seepage control effect-a case study of the Klippe statues' second reinforcement and protection project. Sci Conserv Archaeol. 2019:31:14-25.

14. Yang GL. Review and discussion on the restoration project of Longmen Grottoes. Stud Cave Temples. 2012:3:363-79 (in Chinese).

15. Chen JP. Review and discussion on the restoration project of Double Kilns in Longmen Grottoes in ten years. Stud Cave Temples. 2014;5:430-6 (in Chinese)

16. Veiga R, Velosa A, Magalhaes A. Experimental applications of mortars with pozzolanic additions: characterization and performance evaluation. Constr Build Mater. 2009;23:318-27.

\section{Publisher's Note}

Springer Nature remains neutral with regard to jurisdictional claims in published maps and institutional affiliations.

Received: 5 January 2020 Accepted: 14 May 2020

Published online: 28 May 2020 